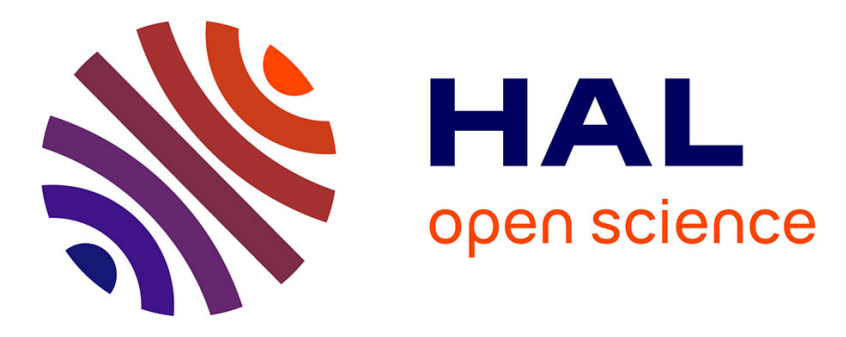

\title{
C-doped AlN/GaN HEMTs for High efficiency mmW applications
}

\author{
Romain Pécheux, Riad Kabouche, Etienne Okada, Malek Zegaoui, F \\ Medjdoub
}

\section{- To cite this version:}

Romain Pécheux, Riad Kabouche, Etienne Okada, Malek Zegaoui, F Medjdoub. C-doped AlN/GaN HEMTs for High efficiency mmW applications. International Workshop on Integrated Nonlinear Microwave and Millimetre-wave Circuits (INMMIC 2018), Jul 2018, Brive La Gaillarde, France. pp.1-3, 10.1109/INMMIC.2018.8430021 . hal-02356756

\section{HAL Id: hal-02356756 https://hal.science/hal-02356756}

Submitted on 2 Dec 2020

HAL is a multi-disciplinary open access archive for the deposit and dissemination of scientific research documents, whether they are published or not. The documents may come from teaching and research institutions in France or abroad, or from public or private research centers.
L'archive ouverte pluridisciplinaire $\mathbf{H A L}$, est destinée au dépôt et à la diffusion de documents scientifiques de niveau recherche, publiés ou non, émanant des établissements d'enseignement et de recherche français ou étrangers, des laboratoires publics ou privés. 


\title{
C-doped AlN/GaN HEMTs for High efficiency mmW applications
}

\author{
R. Pecheux ${ }^{1,2}$, R. Kabouche ${ }^{1}$, E. Okada ${ }^{1}$, M. Zegaoui ${ }^{1}$, and F. Medjdoub ${ }^{1}$ \\ IEMN - CNRS, Institute of Electronics, Microelectronics and Nanotechnology, UMR8520 \\ ${ }^{1}$ Av. Poincaré, 59650 Villeneuve d'Ascq, France \\ ${ }^{2}$ Thales Optronique, 2 Av. Gay Lussac, 78990 Elancourt, France \\ romain.pecheux@etudiant.univ-lille1.fr; farid.medjdoub@iemn.univ-lille1.fr
}

\begin{abstract}
We report on high power-added-efficiency using AIN/GaN heterostructure with a carbon doped buffer layer for millimeter wave applications (C-doped HEMTs). The carbon doped HEMTs show high electrical characteristics with a maximum drain current density $I_{d}$ of $1.5 \mathrm{~A} / \mathrm{mm}$, an extrinsic transconductance $G_{m}$ of $500 \mathrm{mS} / \mathrm{mm}$ and a maximum oscillation frequency $f_{\max }$ above $200 \mathrm{GHz}$ while using a gate length of $120 \mathrm{~nm}$. The high RF performance obtained on the carbon doped HEMT combined to an excellent electron confinement under high bias enabled to achieve a state-of-theart combination at $40 \mathrm{GHz}$ of output power density (Pout $=7$ $\mathrm{W} / \mathrm{mm}$ ) and power added efficiency (PAE) above $50 \%$ up to $V_{D S}=25 \mathrm{~V}$ in pulsed mode.
\end{abstract}

Keywords - high electron mobility transistors (HEMTs), GaN, Carbon doped, output power density and power added efficiency (PAE).

\section{INTRODUCTION}

Owing to its outstanding properties, GaN based High electron Mobility Transistors (HEMTs) are a promising candidate for high frequency high power applications. Especially considering the increasing need in terms of bandwidth wireless communication such as $5 \mathrm{G}$ or SATCOM. One of the key challenge for the GaN technology is to achieve high power-added-efficiency and output-power-density combination in the millimeter-wave range. That is why, the traveling wave tube amplifiers (TWTA) are still widely used in this frame. Even though attractive efficiencies with GaN devices (well-beyond 40\%) have been already demonstrated up to $\mathrm{Ka}$ band [1][2][3][4][5], rather limited PAE has been reported so far in the $\mathrm{Q}$ band $(40 \mathrm{GHz})$ and above. For high frequency applications requiring short gate lengths, different configurations of buffer layers have been employed. One potential solution is the $\mathrm{C}$-doped buffer that has been widely adopted in high voltage power switching applications[6]. It has the advantage compared to Fe-doped GaN buffers of lower memory effects[7], lower risk of diffusion and the elimination of contamination risks when used in Si CMOSbased foundries. In this paper, we demonstrate the potential of the C-doped HEMTs for achieving high output power density combined to high power-added-efficiency at 40 $\mathrm{GHz}$.

\section{MATERIAL AND DEVICE PROCESSING}

The AlN/GaN heterostructures were grown by metal organic chemical vapor deposition (MOCVD) on 4 in. $\mathrm{SiC}$ substrates. The HEMT structure consists of transition layers to $\mathrm{GaN}$, a $1 \mu \mathrm{m}$-thick $\mathrm{C}$-doped $\mathrm{GaN}$ buffer layer followed by an undoped GaN channel, a $4.0 \mathrm{~nm}$ ultrathin AlN barrier layer and a 10 -nm-thick in situ $\mathrm{Si}_{3} \mathrm{~N}_{4}$ cap layer. The in situ $\mathrm{SiN}$ cap layer is used both as early passivation and to prevent strain relaxation [8][9][10]. Room-temperature Hall measurements showed high electron sheet concentrations of $1.8 \times 10^{13}$ with an electron mobility about $1100 \mathrm{~cm}^{2} \mathrm{~V}^{-1} \mathrm{~s}^{-1}$.

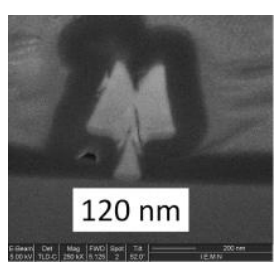

(a)

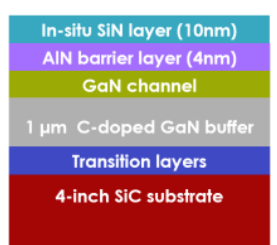

(b)
Fig.21. : a) FIB view of the $0.12 \mu \mathrm{m}$ T-gate and schematic cross section of C-doped HEMT.

A Ti/Al/Ni/Au metal stack followed by a rapid thermal annealed has been used to form the ohmic contacts directly on top of the AlN barrier layer by etching the in situ $\mathrm{Si}_{3} \mathrm{~N}_{4}$ layer. Device isolation was achieved by nitrogen implantation. Ohmic contact resistance $\left(\mathrm{R}_{\mathrm{c}}\right)$ extracted from linear transmission line model (TLM) structures was as low as $0.3 \Omega . \mathrm{mm}$ for both heterostructures. Then, a $0.12 \mu \mathrm{m}$ $\mathrm{Ni} / \mathrm{Au} \mathrm{T}$-gate length was defined by e-beam lithography (see Fig. 2.1). The SiN underneath the gate was fully removed by $\mathrm{SF}_{6}$ plasma etching. The gate-source and gatedrain spacings were 0.3 and $2 \mu \mathrm{m}$, respectively, and the device width was $50 \mu \mathrm{m}$. Finally, $200 \mathrm{~nm} \mathrm{PECVD} \mathrm{Si}_{3} \mathrm{~N}_{4}$ was deposited as final passivation.

\section{DC AND SMALl SIGNAL CHARACTERIZATION}

DC measurements have been carried out using a Keysight A2902A static modular and source monitor. Fig. 3.1 shows the typical I-V characteristics of the structure. The gate source voltage was swept from $-6 \mathrm{~V}$ to $+2 \mathrm{~V}$ with a step of $0.5 \mathrm{~V}$. A maximum current drain density $\left(\mathrm{I}_{\text {Dmax }}\right)$ of 1.5 
$\mathrm{A} / \mathrm{mm}$ is observed at $\mathrm{V}_{\mathrm{DS}}=10 \mathrm{~V}$ and $\mathrm{V}_{\mathrm{GS}}=2 \mathrm{~V}$ reflecting the high carrier concentration.

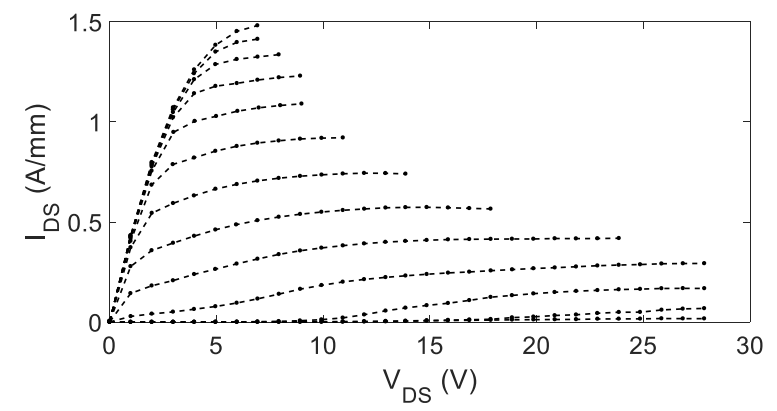

Fig. 3.2 Output characteristics of C-doped HEMT.

From, the transfer characteristics, shown in Fig. 3.2 at $\mathrm{VDS}_{\mathrm{DS}}=$ 6,8 and $10 \mathrm{~V}$, an excellent device pinch-off behavior is observed with a low off-state leakage current below 10 $\mu \mathrm{A} / \mathrm{mm}$. Moreover despite the use of short gate lengths, a good electron confinement is obtained. Furthermore, a high extrinsic transconductance $\mathrm{Gm}_{\mathrm{m}}$ around $500 \mathrm{mS} / \mathrm{mm}$ at $\mathrm{VDS}_{\mathrm{DS}}=10 \mathrm{~V}$ is achieved. At these respective biases, using Rhode and Schwarz ZVA67GHz, the cut-off frequency $\left(\mathrm{f}_{\mathrm{T}}\right)$ and maximum frequency oscillation $\mathrm{f}_{\max }$ are extracted from the scattering (S) parameters. Good RF performances are achieved with $\mathrm{f}_{\mathrm{T}}=60 \mathrm{GHz}$ and $\mathrm{f}_{\max }=242 \mathrm{GHz}$. It can be noticed that a high $f_{\max } / f_{\text {T }}$ ratio above 4 is observed, which can be explained by the favorable aspect ratio between the gate length and the gate to channel distance (ultrathin $4 \mathrm{~nm}$ barrier), the high carrier concentration and the low parasitic gate capacitance.

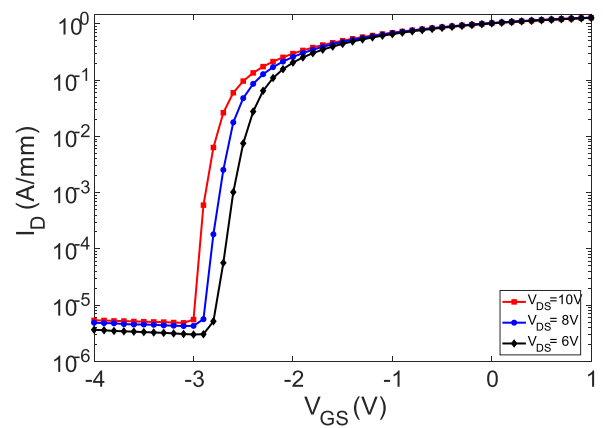

Fig 3.2. : Transfer characteristics at $\mathrm{VDS}=6,8,10 \mathrm{~V}$ of $\mathrm{C}$-doped HEMT.

\section{LARGE SIGNAL CHARACTERIZATION AT $40 \mathrm{GHZ}$}

Large signal characterizations at $40 \mathrm{GHz}$ have been carried out on in pulsed mode ( $1 \mu$ s width and $1 \%$ duty cycle) under deep AB class conditions. Fig 4.1 shows the pulsed power performance of a $0.12 \times 50 \mu \mathrm{m}^{2} \mathrm{AlN} / \mathrm{GaN}$ HEMT at $40 \mathrm{GHz}$ with $\mathrm{V}_{\mathrm{DS}}=15 \mathrm{~V}, 20 \mathrm{~V}$, and $25 \mathrm{~V}$. A saturated Pout (output power density) of $7 \mathrm{~W} / \mathrm{mm}$ was achieved with a peak PAE of $52 \%$ associated to a linear power gain above $8 \mathrm{~dB}$. Moreover, at $\mathrm{V}_{\mathrm{DS}}=10 \mathrm{~V}$ a peak PAE as high as $56 \%$ combined with an output power density of $1.6 \mathrm{~W} / \mathrm{mm}$ has been reached.

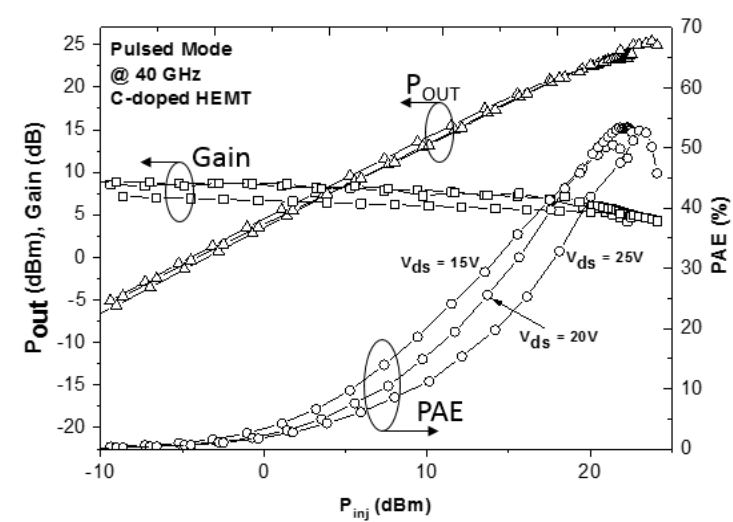

Fig.4.1. : Pulsed power performance of a $0.12 \times 50 \mu \mathrm{m}^{2}$ HEMT at $40 \mathrm{GHz}$ with $\mathrm{V}_{\mathrm{DS}}=15,20,25 \mathrm{~V}$.

The output power density evolves linearly as a function of the drain bias (see Fig 4.2) with no sign of saturation even at $\mathrm{VDS}_{\mathrm{DS}}=25 \mathrm{~V}$ reflecting the high material quality and associated processing. It is worth noting that the C-doped structure shows the ability to deliver a PAE above 50\% up to $\mathrm{VDS}=25 \mathrm{~V}$.

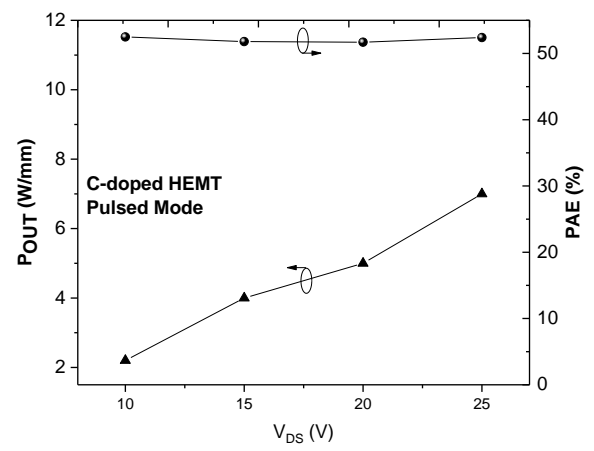

Fig.4.2. : Pulsed output power density (triangle) and PAE (circle) as function of $\mathrm{V}_{\mathrm{DS}}$ at $40 \mathrm{GHz}$.

As can be seen from the benchmark in Fig. 4.3, the achieved PAE / Pout combination at $40 \mathrm{GHz}$ compares favorably to the state-of-the-art.

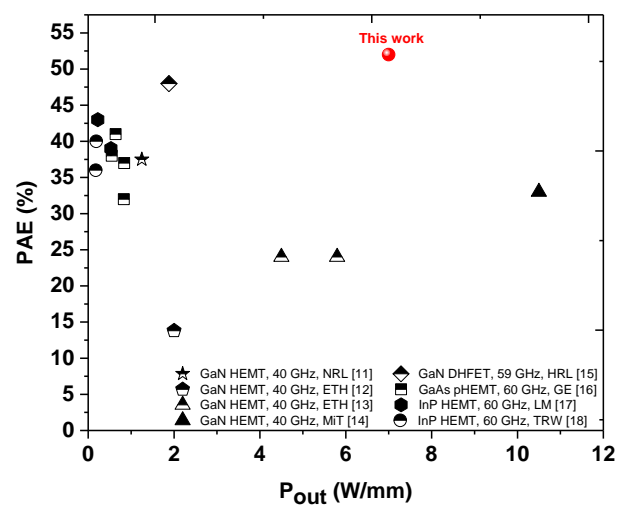

Fig.4.2. : Benchmark of the output RF power density vs PAE for Q and $\mathrm{V}$ band [11] [12] [13] [14] [15] [16] [17] [18]. 


\section{CONCLUSION}

This work shows that a careful architecture of Carbon doped buffer layers can be employed in order to perform high performance millimeter-wave GaN devices. The C-doped structure delivers high performances illustrated by a stateof-the-art combination of PAE (>50\%) and an output power density of $7 \mathrm{~W} / \mathrm{mm}$ at $40 \mathrm{GHz}$ and $\mathrm{V}_{\mathrm{DS}}=25 \mathrm{~V}$.

\section{ACKNOWLEDGMENT}

This work was supported by the French RENATECH network and the French Defense Procurement Agency (DGA) under the project EDA-EuGaNiC and contract FUIVeGaN. The authors would to thank the company EpiGaN for high quality material delivery.

\section{REFERENCES}

[1] P. Saad, H. M. Nemati, M. Thorsell, K. Andersson, and C. Fager, "An inverse class-F GaN HEMT power amplifier with 78\% PAE at $3.5 \mathrm{GHz}$," Eur. Microw. Week 2009, EuMW 2009 Sci. Prog. Qual. Radiofreq. Conf. Proc. - 39th Eur. Microw. Conf. EuMC 2009, no. October, pp. 496-499, 2009.

[2] J. S. Moon et al., " $>70 \%$ power-added-efficiency dual-gate, cascode GaN HEMTs without harmonic tuning," IEEE Electron Device Lett., vol. 37, no. 3, pp. 272-275, 2016.

[3] K. Takagi, S. Takatsuka, Y. Kashiwabara, and S. Teramoto, "Ku-Band AlGaN / GaN-HEMT with over $30 \%$ of PAE," Engineering, pp. 457-460, 2009.

[4] J. S. Moon et al., " $55 \%$ PAE and high power Kaband GaN HEMTs with linearized transconductance via $\mathrm{n}+\mathrm{GaN}$ source contact ledge," IEEE Electron Device Lett., vol. 29, no. 8, pp. 834-837, 2008.

[5] A. Crespo et al., "High-power ka-band performance of AlInN/GaN HEMT with 9.8-nm-thin barrier," IEEE Electron Device Lett., vol. 31, no. 1, pp. 2-4, 2010.

[6] P. Moens, A. Banerjee, P. Coppens, F. Declercq, and M. Tack, "AlGaN / GaN Power Device Technology for High Current ( $100+$ A ) and High Voltage ( 1 . 2 kV )," Proc. 2016 28th ISPSD, Prague, Czech Repub., no. 1, pp. 455-458.

[7] M. J. Uren, J. Moreke, and M. Kuball, "Buffer design to minimize current collapse in GaN/AlGaN HFETs," IEEE Trans. Electron Devices, vol. 59, no. 12, pp. 3327-3333, 2012.

[8] J. Derluyn et al., "Improvement of AlGaN/GaN high electron mobility transistor structures by in situ deposition of a Si3N4 surface layer," J. Appl. Phys., vol. 98, no. 5, p. 54501, 2005.
D. Marcon et al., "Excellent Stability of GaN-on-Si High Electron Mobility Transistors with $5 \mu \mathrm{m}$ Gate-Drain Spacing Tested in Off-State at a Record Drain Voltage of $200 \mathrm{~V}$ and $200{ }^{\circ} \mathrm{C}$," Jpn. J. Appl. Phys., vol. 49, no. 4, p. 04DF07, Apr. 2010.

[10] D. Marcon et al., "High temperature on- and offstate stress of GaN-on-Si HEMTs with in-situ Si3N4cap layer," IEEE Int. Reliab. Phys. Symp. Proc., pp. 146-151, 2010.

[11] B. P. Downey, D. J. Meyer, D. S. Katzer, and J. A. Roussos, "SiNx /InAlN/AlN/GaN MIS-HEMTs With $10.8 \mathrm{THz} \cdot \mathrm{V}$ Johnson Figure of Merit," IEEE Electron Device Lett., vol. 35, no. 5, pp. 527-529, 2014.

[12] D. Marti, S. Tirelli, A. R. Alt, J. Roberts, and C. R. Bolognesi, "150-GHz cutoff frequencies and 2$\mathrm{W} / \mathrm{mm}$ output power at $40 \mathrm{GHz}$ in a millimeterwave AlGaN/GaN HEMT technology on silicon," IEEE Electron Device Lett., vol. 33, no. 10, pp. 1372-1374, 2012.

[13] S. Tirelli, L. Lugani, D. Marti, J. F. Carlin, N. Grandjean, and C. R. Bolognesi, "AlInN-based HEMTs for large-signal operation at $40 \mathrm{GHz}$," IEEE Trans. Electron Devices, vol. 60, no. 10, pp. 3091-3098, 2013.

[14] T. Palacios et al., "High-power AlGaN/GaN HEMTs for Ka-band applications," IEEE Electron Device Lett., vol. 26, no. 11, pp. 781-783, 2005.

[15] M. Micovic et al., "GaN DHFETs Having 48\% Power Added Efficiency and 57\% Drain Efficiency at V-band," IEEE Electron Device Lett., vol. 38, no. 12, pp. 1-1, 2017.

[16] MING-YIH KAO et al., "Very High Power-Added Efficiency and Low-Noise," vol. I, no. 12, pp. 580$582,1989$.

[17] W. M. T. Kong et al., "Very high efficiency V-band power InP HEMT MMICs," IEEE Electron Device Lett., vol. 21, no. 11, pp. 521-523, 2000.

[18] R. Grundbacher et al., "Pseudomorphic InP HEMT's with dry-etched source vias having 190 $\mathrm{mW}$ output power and 40\% PAE at V-band," IEEE Electron Device Lett., vol. 20, no. 10, pp. 517-519, 1999. 